\title{
Sobre a ensinabilidade e a aprendizibilidade da filosofia: reflexões acerca da especificidade do exercício filosófico
}

\author{
About teaching and the appreciability of philosophy: \\ reflections about the specificity of the philosophical \\ exercise
}

Jenerton Alan Schütz ${ }^{1}$

Ivan Luís Schwengber ${ }^{2}$

\begin{abstract}
Resumo:
O presente texto, reflete sobre a relação entre o ensinar e aprender filosofia. As indagações que levantamos neste artigo referem-se ao exercício da filosofia, ou seja, é possível que a filosofia seja "ensinável"? E "aprendível"? Para destrinchar os fios filosóficos das interrogações, o estudo decompõe-se em três partes: i) tematiza a ensinabilidade da filosofia, buscando superar a célebre discussão sobre se se ensina a filosofia ou se ensina a filosofar; ii) problematiza a aprendizibilidade da filosofia; iii) desenvolve a perspectiva da especificidade da filosofia. Ademais, considera que o ensino e a especificidade da filosofia está no ato de criação de conceitos. Caso queiramos um ensino de filosofia "filosófica", necessitamos desenvolvê-lo a partir dos conceitos.
\end{abstract}

Palavras-chave: Ensinar. Aprender. Filosofia.

\begin{abstract}
:
The present text reflects on the relationship between teaching and learning philosophy. The questions we raise in this article refer to the exercise of philosophy, ie is it possible that philosophy is "teachable"? Is it "learnable"? In order to unravel the philosophical threads of the interrogations, the study is divided into three parts: i) the thematic philosophy of philosophy, seeking to overcome the famous discussion about whether philosophy is taught or taught philosophizing; ii) problematizes the learning of philosophy; iii) develops the perspective of the specificity of philosophy. In addition, it considers that the teaching and the specificity of the philosophy is in the act of creating concepts. If we want a teaching of "philosophical" philosophy, we need to develop it from the concepts.
\end{abstract}

Keywords: Teaching. Learn. Philosophy.

\footnotetext{
${ }^{1}$ Universidade Regional do Noroeste do Estado do Rio Grande do Sul (UNIJUI). Doutorando em Educação nas Ciências (UNIJUI).

${ }^{2}$ Universidade Comunitária da Região de Chapecó. Mestrando em Educação pela UNOCHAPECÓ
} 


\section{1 - Introdução}

Na obra Ecce Hommo - como alguém se torna o que é de 1888, Nietzsche apresenta uma espécie de autobiografia intelectual, um balanço de sua vida e de seus escritos. Sobre o exercício da filosofia, ele escreveu que: “[...] filosofia, tal como até agora a entendi e vivi, é a vida voluntária no gelo e nos cumes - a busca de tudo o que é estranho e questionável no existir, de tudo o que a moral até agora baniu” (1995, p. 18). Não obstante, seria o mesmo que dizer que a filosofia é um exercício de e na solidão.

A figura de Zaratustra é ilustrativa para a noção de filósofo que acompanha essa concepção de filosofia. Aos trinta anos, ele deixa sua terra natal e vai para a montanha, onde permanece por uma década, gozando “[...] de seu próprio espírito e solidão" (NIETZSCHE, 1994, p. 27). Na montanha, na solidão e no silêncio, produz-se a altivez espiritual e a "[...] arrepiante certeza da qual é impregnado e tingido, de mediante seu sofrimento saber mais do que os mais inteligentes e sábios poderiam saber, de ter estado e ser versado em tantos mundos distantes e horríveis, dos quais 'vocês nada sabem'! [...]” (NIETZSCHE, 1992, p. 186). Nesse contexto, a filosofia pode ser definida como uma ação do artista que plasma, talha seu próprio espírito. É o filósofo esse artista, o escultor, mas também a pedra que se modela por meio de duros golpes de martelo que não se aplicam a outros, mas a si mesmo. A filosofia só tem sentido para quem tem uma vida de sobressaltos, riscos e aventuras, permeada por sofrimentos, silêncio, solidão e dor.

Como sabiamente ressalta Alcibíades no seu elogio a Sócrates, somente aqueles que já foram mordidos pela serpente - da filosofia - “[...] estão em condições de avaliar e de desculpar as loucuras feitas ou relatadas pelo indivíduo sob a influência da dor" (PLATÃO, 2001, p. 85). Contudo, para além da experiência da mordida, Alcibíades afirma: "Eu fui mordido por algo mais doloroso e no ponto mais sensível do meu ser: o coração ou a alma - o nome pouco importa - pelos discursos filosóficos, de ação mais 
profunda do que a do veneno das víboras, quando atuam na alma jovem e bem nascida e a levam a tudo dizer e realizar" (PLATÃO, 2001, p. 85). A experiência do assombro de Alcebíades ter encontrado a episteme (conhecimento científico/verdadeiro), experiência dolorosa porque leva a mudança radical.

Assim como para Platão, a saída da caverna é um caminho inóspito, um exercício de saída da doxa (do senso comum, vulgar/opinião), para Nietzsche, uma saída do alto do cume isolado, ambos percebem a dor e a solidão no exercício da filosofia. Entretanto, uma filosofia que resiste à facticidade e ingenuidade.

Traduzindo para o contexto deste estudo, isso significa dizer que é a partir, e sob o efeito da mordida "filosófica", que procura-se abordar a relação entre Filosofia e Ensino. A dor sentida pelo veneno filosófico provocou inquietações e motivações para o estudo, pois, não podemos nos acomodar a certezas fáceis, necessitamos questioná-las, de novo e uma vez mais. É o convite que fica. Nessa direção, devemos nos indagar sobre a filosofia, sendo esta um exercício de solidão, é possível que seja “ensinável”? E “aprendível”? É presumível que possa ser transmitida de um indivíduo a outro? Ou então devemos aceitar que a filosofia não se transmite, não se ensina e não se aprende?

Objetiva-se, portanto, discutir as questões supracitadas e suas implicações para o campo da Filosofia e do Ensino, além disso, o manuscrito baseia-se em pesquisa interpretativa, com apoio em referências bibliográficas de pesquisadores que analisam e exploram a temática.

Inicia-se pela ensinabilidade da filosofia, buscando superar a célebre discussão sobre se se ensina a filosofia ou se ensina a filosofar, grosso modo, há algo de específico em se ensinar filosofia? Ou, como nos lembra Comenius, é uma arte de ensinar tudo a todos, ou ensinamos através de uma didática específica? Por conseguinte, desenvolve-se a perspectiva da especificidade da filosofia, portanto, também de seu ensino, que está no ato de criação de conceitos. É este ato que torna a filosofia propriamente 
filosofia, caso queiramos um ensino de filosofia "filosófica", necessitamos desenvolvê-lo a partir dos conceitos.

Ademais, a ideia é a de se organizar uma aula de filosofia como se fosse uma verdadeira fábrica de conceitos, na qual professor e alunos versem sobre os conceitos criados ao longo da história da filosofia entendida como uma leitura filosófica de filosofias já constituídas - como ferramentas a serviço da resolução de problemas e, a partir de problemas peculiares, busquem também a criação de conceitos filosóficos.

\section{2 - Sobre a "ensinabilidade" da filosofia}

$\mathrm{O}$ verbo ensinar, do latim insignare, significa textualmente 'colocar um significado', 'colocar um exemplo', 'marcar com um sinal' e 'despertar para o conhecimento'. Há muitas formas de ensinar. Mas, afinal, por que defender o ensino de filosofia?

Fernando Savater, em seu livro, As Perguntas da Vida (2001) faz a mesma pergunta: há sentido em se defender o ensino de filosofia na educação básica (ensino médio) em nossos dias? E ele respondeu:

Tem sentido empenhar-se hoje, [...], em manter a filosofia como uma matéria a mais no bacharelado ${ }^{3}$ ? Trata-se de mera sobrevivência do passado, que os conservadores enaltecem por seu prestígio tradicional mas que os progressistas e as pessoas práticas devem encarar com justificada impaciência? Podem os jovens, ou adolescentes, inclusive crianças, entender claramente algo que em sua idade deve parecer obscuro? Não se limitarão, na melhor das hipóteses, a memorizar algumas fórmulas pedantes que depois repetirão como papagaios? Talvez a filosofia interesse a alguns poucos, aos que têm vocação filosófica, se é que isso ainda existe, mas esses, de qualquer modo, terão tempo de descobri-la mais adiante. Então para que impô-la a todos no secundário? Não é uma perda de tempo infundada e

\footnotetext{
${ }^{3} \mathrm{O}$ fato de o autor ser espanhol, a expressão 'Bachillerato' remete ao ensino médio espanhol.
}

Filos. e Educ., Campinas, SP, v.10, n.2, p.331-349, maio/ago. 2018 - ISSN 1984-9605 
reacionária, em vista da sobrecarga dos atuais programas de ensino médio? (2001, p. 3).

Num contexto de mundo e escola voltados excessivamente para a informação e as tecnologias, Savater considera que a filosofia não teria mesmo nada a oferecer. Além disso, o autor afirma que podemos falar em três níveis de compreensão: a informação, o conhecimento e a sabedoria; enquanto a ciência transita entre a informação e o conhecimento, a filosofia move-se entre o conhecimento e a sabedoria (SAVATER, 2001). Não obstante, “[...] não há informação propriamente filosófica, mas pode haver conhecimento filosófico, e gostaríamos de chegar a que houvesse também sabedoria filosófica. É possível conseguir tal coisa? Sobretudo: é possível ensinar tal coisa" (SAVATER, 2001, p. 6). Ademais, seria possível ensinar filosofia?

O autor não hesita em responder de maneira positiva, de tal modo que faz uma extensa argumentação em torno da filosofia como atividade, processo, e não apenas como conjunto de conhecimentos historicamente produzidos, para concluir que é possível ensinar a filosofar, como busca de respostas cada vez melhores para os problemas com os quais nos defrontamos. E, indo além, se a educação pretende ser humanizadora, ela não pode prescindir da filosofia. A questão que se coloca é: como então ensinar os jovens a filosofar?

A perspectiva de Savater é a de que o ensino da filosofia deve ser feito a partir e através de grandes temáticas, como a morte, a liberdade, a beleza, o tempo, a convivência - para citar alguns -, que devem ser trabalhados de forma problematizadora. Em outras palavras, esses temas devem ser tratados como problemas filosóficos, que enfrentamos diariamente, e que vêm recebendo diferentes contornos ao longo da história.

Tornar os conhecimentos cotidianos questões filosóficas, numa linguagem platônica, parte-se da doxa para chegar a episteme, já que a doxa é o lugar comum de onde possamos significar o conhecimento filosófico (é necessário revisar esta frase). Assim, na mesma medida em que os jovens são levados a pensar sobre esses problemas, que em maior ou menor medida 
todos experimentamos, em diferentes momentos de nossas vidas, também tomam contato com diferentes filósofos que, nas mais diversas épocas, se incomodaram com esses mesmos problemas e procuraram construir formas de equacioná-los que, se não nos dão uma resposta definitiva, ao menos ajudam-nos a compreendê-los de um modo melhor, assim como nosso mundo e a nós mesmos.

Em um texto escrito em 1995, Savater já havia lançado luzes para pensarmos o tema, colocando sempre a polêmica questão do como e por que ensinar filosofia. O autor resgata as várias e diferentes críticas produzidas no pensamento filosófico (recordamos Montaigne, Schopenhauer, Nietzsche, Sartre, Adorno, Horkheimer, para ficarmos em apenas alguns) a uma filosofia sistematizada nas e pelas escolas, que tira dela toda sua força e potencial criativo, recolocando a questão do ensino da filosofia voltado para o ato do filosofar ou para o conteúdo da filosofia.

A dificuldade de ensinar filosofia é que esta disciplina consiste mais numa atitude intelectual do que num conjunto bem estabelecido de conhecimentos, cada um dos quais poderia ser separado sem diminuição de sua força assertiva do nome do seu descobridor. Por isso, a via pedagógica mais evidente, quase irremediável, passa pelo estudo de cada uma das grandes figuras do tarot filosófico (como quem diz, os seus Arcanos Maiores) pois a comemoração de tais exemplos da filosofia em marcha - quando bem feita - é o mais estimulante para o aluno e terreno mais seguro para o professor [...]. A recomendação kantiana de que não se deve ensinar filosofia mas sim a filosofar condensa num lema a dificuldade, mas não a resolve. $\mathrm{O}$ distintivo do filósofo não é arengar às massas nem sequer doutrinar grupos de estudo, mas comunicar o individualmente pensado a um interlocutor também único e irrepetível (SAVATER, 2000, p. 31).

Em Kant, há uma ênfase significativa no exercício da razão, o ato de filosofar expresso pelo verbo filosofar e a problemática já fora percebido: "Dentre todas as ciências racionais ( $a$ priori), portanto, só é possível aprender Matemática, mas jamais Filosofia (a não ser historicamente); no 
que tange à razão, o máximo que se pode aprender é filosofar" (KANT, 1983, p. 407). Isso leva a impactar a forma de ensinar filosofia, pois em Kant, rigorosamente, só é possível o exercício do pensamento subjetivo. Mas na passagem da Crítica da Razão Pura (1788) da arquitetônica do sistema filosófico enquanto maturidade intelectual, nota-se o aspecto emancipador do sujeito pelo exercício da razão.

Afirmar a importância do ato do filosofar para o ensino de filosofia não nos autoriza a prescindir do conteúdo filosófico, daquilo que foi historicamente produzido pela atividade do pensar:

A atividade filosófica actual prolonga uma tradição cuja própria memória já é uma parte importante do âmbito da sua reflexão. Seria não simplesmente pretensioso, mas sobretudo ridículo e ineficaz tentar filosofar sobre qualquer tema, esquecendo ou desdenhando a constância do já pensado sobre ele ou do pensado que pode relacionarse com ele [...]. A recordação dos filósofos é o que hoje nos legitima para filosofar (SAVATER, 2000, pp. 29-30).

Nessa direção, se, ao ensinarmos filosofia, nos limitarmos a expor figuras e momentos da história da filosofia, estaremos contribuindo para afirmar a filosofia como peça(s) de museu, como algo que se contempla, se admira, que se vê a distância, como algo intangível para nós. Mas, de outro modo, se nos dedicarmos ao ensino da filosofia, buscando o processo do filosofar permanente nos esquecendo daquilo que foi historicamente produzido, perderemos a legitimidade para tal ato.

Se não buscarmos o sentido no fio proveniente da tradição, o pensamento se vê, assim, na difícil tarefa de encontrar o sentido sem poder contar com os padrões universais estabelecidos como tais pelo passado. A "herança sem testamento", como a situação do pensamento no mundo contemporâneo, que nos alerta Arendt na obra Entre o Passado e o Futuro (2013), obriga a filosofia a se reconciliar com a existência e a buscar a sua significação no seu âmbito mesmo, e não em outro mundo ou numa legalidade ou conhecimento do curso histórico no seu todo. 
Não obstante, recusar a tradição do pensamento filosófico (história da filosofia), que é a única maneira de manter viva a história, continuamente criando e (re)produzindo, só é possível a partir dessa mesma tradição, pois, nada criaremos, se não a tomarmos como ponto de partida. Lembramos que o crescente elogio da inovação, considera a inovação como uma produção do futuro que não está ancorada no passado, como se fosse possível criar a partir do nada. Consideramos: se há deus, ele cria a partir do nada, os homens não criam a partir do nada, os homens criam a partir do velho, do passado, pois é essa a base da nossa inovação.

Não há como progredir numa ideia de inovação sem respeitar o velho, a tradição, a memória. Não se faz arte moderna sem conhecer a arte clássica, não se faz qualquer trabalho investigativo - artigo, monografia, dissertação, tese -, sem conhecer aquilo que chamamos de "estado da arte", ou seja, revisão daquilo que já foi feito sobre determinado assunto, o que exige um olhar para o passado.

Adquirir os conhecimentos fundamentais que a humanidade foi lentamente construindo, as teorias explicativas básicas necessárias à compreensão geral do mundo em que vivemos e dos Outros que aqui habitam, as suas determinações históricas, filosóficas, sociológicas e artísticas mais decisivas, um domínio alegre e satisfatório da sua língua, outras línguas e outras maneiras de ver o mundo, destrezas físicas e intelectuais. Trata-se, portanto, de transmitir isso sem impor morais, sem apontar modos de vida, sem sugerir cenários de felicidade na Terra ou fora dela (POMBO, 2002), essa é a regra. Ademais, para finalizar essa primeira seção, recorre-se novamente a Savater. Para ele, há quatro posturas que um professor de filosofia deve manter:

- primeira, que não existe 'a' filosofia, mas 'as' filosofias e, sobretudo, o filosofar [...]. Há uma perspectiva filosófica [...], mas felizmente ela é multifacetada [...].

- segunda, que o estudo da filosofia não é interessante porque a ela se dedicaram talentos extraordinários como Aristóteles ou Kant, mas esses talentos nos interessam porque se ocuparam dessas questões de

Filos. e Educ., Campinas, SP, v.10, n.2, p.331-349, maio/ago. 2018 - ISSN 1984-9605 
amplo alcance que são tão importantes para nossa própria vida humana, racional e civilizada [...].

- terceira, que até os melhores filósofos disseram absurdos notórios e cometeram erros graves. Quem mais se arrisca a pensar fora dos caminhos intelectualmente trilhados corre mais riscos de se equivocar, e digo isso como elogio e não como censura [...].

- quarta, que em determinadas questões extremamente gerais aprender a perguntar bem também é aprender a desconfiar das respostas demasiado taxativas [...]. (SAVATER, 2001, pp. 209-210).

O autor nos leva a considerar pulsante, que o ensino de filosofia deve manter sua atitude primordial, que é o filosofar, não importa necessariamente sobre o que filosofar, mas a atitude crítica de estar sempre numa atividade singular do questionar, indagar o mundo da vida; esta atividade não é privilégio de um guru, de um mestre, mas um saber acessível, democrático, para quem se propõe a subir nos altos cumes. Isto implica em compreender a falibilidade do conhecimento humano, pois podemos ser somente amigos do conhecimento (philo-sophia) e nunca detentores da sabedoria, o que implica manter-se em constante suspeita sobre a possibilidade de alcançar a verdade.

Ensinar filosofia é um exercício de apelo à diversidade; é um exercício de acesso a questões fundamentais para a existência humana; é um exercício de abertura ao risco, de busca da criatividade, de um pensamento sempre fresco; é um exercício da pergunta e da desconfiança da resposta fácil. Quem não estiver disposto a tais exercícios, dificilmente encontrará prazer e êxito nesta aventura que é ensinar filosofia, aprender filosofia. Ademais, como a etimologia sugere, talvez a ensinabilidade tenha a ver com propiciar sinais, marcas que os outros possam seguir. Quem sabe também esteja ligada a oferecer um exemplo por parte de alguém que, também e sobretudo, aprende.

O debate sobre a filosofia, conteúdo e método, não se encerra, há somente uma perspectiva pós-moderna de manter a pulsão e o espírito da filosofia na educação, enquanto forma de questionar a realidade, é neste 
sentido que a filosofia nunca terá um lugar seguro, o ensino de filosofia nunca será algo repousante; mas uma atitude de dor e de solidão; e para quem se propõe a atividade de filosofar com jovens, vai diariamente ter que responder o por que de se ensinar filosofia para jovens, e consequentemente, filosofar.

\section{3 - Sobre a "aprendizibilidade" da filosofia}

Como nos posicionamos a favor da ensinabilidade da filosofia, devemos agora nos perguntar se ela é "aprendível". Os neologismos aqui utilizados não soam muito bem, causam desconforto. Exatamente por isso que os utilizamos. De fato, estamos demasiadamente acomodados com o fato de que algo que é ensinado é passível de ser aprendido. Entretanto, isso nem sempre acontece. A pedagogia inclusive cunhou a expressão "ensinoaprendizagem", buscando denotar a via de mão dupla na qual deve se constituir esse processo, mas a expressão (como tantas outras) caiu num modismo maneiro e penso que já não significa grande coisa.

É fundamental que desconfiemos daquilo que se apresenta como uma certeza fácil de que isso é ensinado e aprendido, ou, de que tudo o que é transmitido é assimilado, destarte, as sementes podem ou não germinar, depende do solo em que são lançadas. Pois bem, ensinar é lançar sementes, que não sabemos se germinarão ou não; já aprender é incorporar a semente, fazê-la germinar, crescer e frutificar, produzindo o novo, o imprevisível.

Disso podemos considerar que não necessariamente o que é ensinado é aprendido. No processo da aprendizagem não conseguimos exercer um controle absoluto, podemos planejar, executar tudo aquilo que leva horas para esquematizar, tomar todos os cuidados imagináveis, mas sempre algo poderá escapar do controle, trazendo à luz um resultado insuspeitado, inimaginável, inesperado. E esta é a beleza do processo educativo: agir, sem nunca saber qual será o resultado (concreto) de nossas ações. Ademais, uma aula pode "funcionar" muito bem em nossas cabeças, mas pode produzir situações e resultados totalmente divergentes nos alunos. 
E assim lançamos as nossas sementes, sem saber se darão origem a flores ou a monstros (bárbaros), ou mesmo a coisa alguma. A dose de incerteza presente no processo educativo, é a grande pedra no caminho de uma pedagogia moderna que se quis fazer ciência, sendo já identificada por Deleuze na década de 60:

Nunca se sabe de antemão como alguém vai aprender - que amores tornam alguém bom em Latim, por meio de que encontros se é filósofo, em que dicionários se aprende a pensar. Os limites das faculdades se encaixam uns nos outros sob a forma quebrada daquilo que traz e transmite a diferença. Não há método para encontrar tesouros nem para aprender, mas um violento adestramento, uma cultura ou paideia que percorre inteiramente todo o indivíduo [...]. O método é o meio de saber quem regula a colaboração de todas as faculdades; além disso, ele é a manifestação de um senso comum ou a realização de uma Cogitatio natura, pressupondo uma boa vontade como uma 'decisão premeditada' do pensador. Mas a cultura é o movimento de aprender, a aventura do involuntário, encadeando uma sensibilidade, uma memória, depois um pensamento, com todas as violências e crueldades necessárias, dizia Nietzsche, justamente para 'adestrar um povo de pensadores', 'adestrar o espírito' (DELEUZE, 1988, p. 270).

O que Deleuze quer nos dizer é que nem todos que leem filosofia, ouvem falar de filosofia, falam de filosofia vão necessariamente filosofar. Para dizer com Nietzsche, não somente a dor e a solidão dos altos cumes que vão fazer filosofar, porque em Deleuze, há a diferença radical das faculdades de sujeitos, que nem sequer são uma subjetividade, mas um mosaico de momentos.

Nessa direção, consideramos que até pode haver métodos para ensinar, o que, pelo menos, serve para tranquilizar as consciências perturbadoras dos professores, mas não há métodos para aprender. O método é uma máquina de controle, mas a aprendizagem está para além de 
qualquer controle. Para e na filosofia, isso é fundamental, mais uma consideração de Deleuze e poderemos completar o raciocínio.

Aprender vem a ser tão-somente o intermediário entre não-saber e saber, a passagem viva de um ao outro. Pode-se dizer que aprender, afinal de contas, é uma tarefa infinita, mas esta não deixa de ser rejeitada para o lado das circunstâncias e da aquisição, posta para fora da essência supostamente simples do saber como inatismo, elemento $a$ priori ou mesmo ideia reguladora. E, finalmente, a aprendizagem está, antes de mais nada, do lado do rato no labirinto, ao passo que o filósofo fora da caverna considera somente o resultado - o saber para dele extrair os princípios transcendentais (DELEUZE, 1988, p. 271).

O aprender está na busca do mistério, que não se esgota em última instância; sem desconsiderar que as relações que estabelecemos são significativas, pois não há conhecimento dado de forma inata ou a priori, mas uma busca do sujeito em suas relações. Não podemos circunscrever o aprendizado nos limites de uma aula, da audição de uma conferência, da leitura de um livro; ele ultrapassa qualquer fronteira, rasga os mapas e pode inaugurar múltiplas possibilidades e horizontes sem limites.

Afinal, o que é o processo do filosofar, senão essa busca por horizontes para questioná-los uma vez e outra mais, para descobrir que não há horizontes? Com as palavras de Deleuze podemos inferir que o processo do filosofar é análogo ao processo de aprendizagem: o hiato entre o saber e o não-saber; phylosophia, movimento do não-saber à sabedoria, sem nunca alcançar essa última, mas jamais retornando ao primeiro.

É preciso reagir contra o conformismo, tomando a filosofia como movimento de rasgar o caos, atravessá-lo e nos ensinar a conviver com ele, num movimento de recusa à opinião generalizante e paralisante de criação. O filósofo “[...] parece retornar do país dos mortos" (DELEUZE \& GUATTARI, 1992, p. 260), ou seja, ir ao mundo dos mortos e voltar, com novos elementos criativos, eis o que pode nos proporcionar a filosofia. Nossas aulas de filosofia, portanto, devem ser visitas ao mundo dos mortos, 
devem ser exercícios de mergulho no caos para dele trazer novas potencialidades. Devem ser, enfim, um exercício de recusa da opinião.

E assim, o filósofo é um aprendiz. Está mais para o rato no labirinto, que precisa aprender/encontrar a saída; está mais para o sujeito de dentro da caverna, que descobre sua condição e procura saída, do que para o sujeito já fora da caverna, que contempla o verdadeiro saber (a ideia). No primeiro, temos a imanência do problema; no segundo, a transcendência da solução, já posta desde sempre. Nesse contexto, a questão sobre a "aprendizibilidade" da filosofia se resolve: sim, a filosofia é aprendizagem!

\section{4 - Sobre a especificidade da filosofia}

Se consideramos que a filosofia é uma didática geral, uma arte ou um método de ensinar tudo a todos, então falhamos, ou seja, isso não pode dar conta do ensinar e aprender filosofia. Filosoficamente, o aprender filosofia está para além de qualquer método, que significa controle. A filosofia, no processo de ensino e aprendizagem, sempre nos escapa. No entanto, cremos que é necessário nos dedicar a essa aventura que é o ensino de filosofia. Reiteramos, aventura, isto mesmo, pois sabemos quando e de onde saímos, mas não sabemos quando, aonde ou mesmo se chegaremos.

O ensino da filosofia não pode ser dotado de uma didática geral, não pode ser equacionado unicamente como uma questão pedagógica porque há algo de específico na filosofia. Há algo que faz com que a filosofia seja filosofia, e não ciência, e não religião, muito menos opinião.

Afinal, o que é específico da filosofia?

O que faz a filosofia filosofia e não outra coisa qualquer é o trato com o conceito, como apontaram Deleuze e Guattari na obra $O$ que é a filosofia?, para eles, a perspectiva do que distingue a filosofia de outros saberes é que apenas ela produz (cria) conceitos. A arte cria afetos e a ciência cria funções para exprimir o real, a primeira com ênfase numa perspectiva estética e a segunda com caráter empírico-racional. 
Se a filosofia produz (cria) conceitos, como entender o conceito? Digamos que ele seja uma forma de pensamento, criado pelos gregos nômades do mundo antigo em contraposição aos sábios orientais, que pensavam por imagens. Mas um pensamento com direção: o conceito é sempre criado a partir de uma problemática ou um conjunto delas. Assim, o conceito é uma forma racional de equacionar um problema ou problemas, exprimindo uma visão coerente do vivido. Não é abstrato nem transcendente, mas imanente, uma vez que parte necessariamente de problemas experimentados. Nunca o conceito é oferecido de antemão, sempre é criado. Na etimologia, significa: dar vida, trazer à luz, não obstante, concebemos conceitos como concebemos filhos, como brotam as sementes.

Os conceitos nunca são conclusivos, sempre estão "abertos", carregando em si os problemas originários, além de contribuírem para o aparecimento de novos problemas. Este conceito aparece fortemente na obra O que é a filosofia? (1992),

Um problema não existe fora de suas soluções. Mas, em vez de desaparecer, ele insiste e persiste nas soluções que o recobrem. Um problema se determina ao mesmo tempo em que é resolvido; mas sua determinação não se confunde com a solução: os dois elementos diferem por natureza, e a determinação é como a gênese da solução concomitante [...]. O problema é ao mesmo tempo transcendente e imanente em relação a suas soluções. Transcendente, porque consiste num sistema de ligações ideais ou de relações diferenciais entre elementos genéticos. Imanente, porque estas ligações ou relações se encarnam nas correlações atuais que não se assemelham a elas e que são definidas pelo campo de solução (DELEUZE \& GUATTARI, 1992, p. 267).

Persistência do problema. Graça e desgraça da filosofia, que faz dela mesma uma atividade perpétua, quem sabe até infinita, de criação de conceitos para lançar luz sobre problemas que sempre estão reaparecendo, num eterno jogo de claro/escuro o que faz da vida ser o que ela é. Se 
assumirmos que a especificidade (identidade) da filosofia reside no ato da criação de conceitos e que esses, por sua vez, referem-se a problemas, a discussão e a prática do ensino de filosofia deverão, fundamentalmente, passar pelo conceito e pelos problemas, chaves para esta discussão e prática.

Se, como já consideramos, a aprendizagem é o hiato entre saber e nãosaber, em filosofia a aprendizagem é o hiato entre o não-filósofo e o filósofo. De tal modo que, o professor de filosofia é aquele que, sendo filósofo (exercita a filosofia) deve fazer-se não-filósofo para, no contato com os alunos, (re)descobrir o ato filosófico, na medida em que eles o descobrem. Não obstante,

[...] o filósofo deve tornar-se não-filósofo, para que a não-filosofia se torne a terra e o povo da filosofia [...]. Tornar-se estrangeiro a si mesmo, e à sua própria língua e nação, não é o próprio do filósofo e da filosofia, seu 'estilo', o que se chama um galimatias filosófico? (DELEUZE \& GUATTARI, 1992, pp. 142-143).

Para possibilitar o jogo do aprender, é preciso que o professor se apresente não como aquele que já sabe - um pedante, mas como aquele que está em constante busca pela suspeita, não se satisfazendo com qualquer resposta (que se dá “de vez”). Buscar a linguagem dos alunos, identificar-se com eles, sem tornar-se mais um deles, sentir e pensar com eles, para que o ato filosófico se dê.

Fazer-se estrangeiro a si mesmo: não seria isso respirar o ar gelado dos cumes, no dizer de Nietzsche? A aventura do ensino de filosofia não seria, ela mesma, a possibilidade viva de um sempre renascer da filosofia? Para compreender este tipo de atividade há necessidade do educador voltar a caverna para que possa ser compreendido pelos seus, então a proposta é que em algum momento deve descer das montanhas para instigar outros a ir ao cume. Esta atividade é compreendia por Boaventura de Souza Santos como a atividade da tradução.

O trabalho de tradução visa esclarecer o que une e o que separa os diferentes movimentos e as diferentes práticas de modo a determinar 
as possibilidades e os limites da articulação ou agregação entre eles. Dado que não há uma prática social ou um sujeito colectivo privilegiado em abstracto para conferir sentido e direcção à história, o trabalho de tradução é decisivo para definir, em concreto, em cada momento e contexto histórico, quais as constelações de práticas com maior potencial contra-hegemónico. (SANTOS, 2004, p. 806).

Trabalho de tradução é fundamental para que a conhecimento filosófico responda as perguntas cotidianas, que diga ao educando que a filosofia não é uma atividade restrita de filósofos especialistas, mas que é possível fazer filosofia cotidianamente, desde que se proponha ir aos cumes e sentir a dor da picada da serpente.

A tradução é, simultaneamente, um trabalho intelectual e um trabalho político. E é também um trabalho emocional porque pressupõe o inconformismo perante uma carência decorrente do carácter incompleto ou deficiente de um dado conhecimento ou de uma dada prática. (SANTOS, 2004, p. 808).

Surge assim entre a episteme e a doxa uma zona de contatos: "Zonas de contacto são campos sociais onde diferentes mundos-da-vida normativos, práticas e conhecimentos se encontram, chocam e interagem". (SANTOS, 2004, p. 808). Com isto agregando significados. São saberes e práticas de cada zona de contato único, enquanto postas em contato com aluno.

Buscar a linguagem dos alunos, identificar-se com eles, sem tornar-se mais um deles, sentir e pensar com eles, para que o ato filosófico aconteça. Fazer-se estrangeiro a si mesmo, não seria isso respirar o ar gelado dos cumes, no dizer nietzschiano? A aventura do ensino de filosofia não seria, ela mesma, a possibilidade viva de um sempre renascer filosófico?

Por esse modo, a aula de filosofia deve ser vista como uma oficina de conceitos, e não uma aula de museu, como já reiteramos, na qual se contemplam conceitos criados há muito tempo e que são vistos como meras curiosidades, mas como um local de trabalho, onde os conceitos sejam 
ferramentas manejáveis, como um laboratório, onde se façam experiências com os diversos conceitos.

Dessa forma, teremos na sala de aula a filosofia como uma atividade, como um processo, e não como um produto. Conceitos a serem criados, recriados, retomados, renovados, em lugar de conceitos sempre já presentes a serem decorados para a próxima avaliação. Pois, “[...] pensar é experimentar, mas a experimentação é sempre o que se está fazendo - o novo, o notável, o interessante, que substituem a aparência de verdade e que são mais exigentes que ela" (DELEUZE \& GUATTARI, 1992, p. 143).

O pensar é um desafio sem fim que examina os acontecimentos recentes e retoma o que já foi pensado à luz de novas experiências. É legítimo repensar um assunto, uma vez que a atividade do espírito é produzir resultados sempre provisórios, que serão retomados em novas reflexões. Nas palavras de Almeida (2011, p. 156), “[...] nossos pensamentos não são definitivos, nem chegam a resultados duráveis". Por isso, "o pensamento é como a teia de Penélope, desfaz-se toda manhã o que se terminou de fazer na noite anterior" (ARENDT, 1993, p. 69), e esse é o sentido de ensinar e aprender filosofia.

\section{5 - Considerações finais}

Num momento em que o ensino e a educação estão sendo repensados, em nível de políticas públicas, a discussão sobre a filosofia começa a ser recorrente, principalmente, sobre o que ensinar e por que ensinar filosofia para os jovens. Outrossim, este texto é uma argumentação a favor da ensinabilidade e aprendizibilidade da filosofia.

Quanto a ensinabilidade da filosofia, concluímos que ensinar filosofia é um exercício de apelo à diversidade, ao perspectivismo; é um constante exercício de acesso a questões fundamentais para a existência humana; é um exercício de abertura ao novo, ao risco, de busca da criatividade, de um pensamento sempre fresco; é um exercício da pergunta que desconfia da resposta fácil. Quem não estiver disposto a tais exercícios, dificilmente 
encontrará prazer e êxito na aventura que é ensinar filosofia, aprender filosofia.

A perspectiva deleuziana considera o filósofo como um eterno aprendiz. É como o rato que está no labirinto e precisa aprender a encontrar a saída; é como o sujeito dentro da caverna, que descobre sua condição e procura a sua saída, do que para o sujeito que já fora da caverna, que contempla o verdadeiro saber (ideia).

Portanto, com Deleuze, pensar é produzir conceitos, mas conceitos como ponto de partida, em tal empreitada não podemos partir para a autonomia da razão, mas sim, de um conhecimento falível e compreendido no sentido terapêutico, fazer o sujeito compreender-se em suas diferentes identidades, ou momentos que transpassam a subjetividade, seu estilo. Assim, não se ensina filosofia impunemente; não se aprende filosofia impunemente. A especificidade da "oficina de conceitos" é um local perigoso, de onde podem surgir conceitos que sejam ferramentas para mudar o mundo.

Dessa forma, teremos na sala de aula a filosofia como uma atividade, como um processo, e não como um produto. Conceitos a serem criados, recriados, retomados, renovados, em lugar de conceitos sempre já presentes a serem decorados para a próxima avaliação. Nunca o conceito é oferecido de antemão, sempre é criado. Na etimologia, significa: dar vida, trazer à luz, não obstante, concebemos conceitos como concebemos filhos, como brotam as sementes, é isso que esperamos da ensinabilidade e aprendizibilidade filosófica.

Fica aqui o registro para que as preocupações assumidas neste estudo, e as inquietações que dele emerjam, possam levar a outros caminhos, novas pesquisas, novos problemas e possibilidades.

\section{Referências}

ALMEIDA, V. S. de. Educação em Hannah Arendt: entre o mundo deserto e o amor ao mundo. São Paulo: Cortez, 2011.

Filos. e Educ., Campinas, SP, v.10, n.2, p.331-349, maio/ago. 2018 - ISSN 1984-9605 
ARENDT, H. Entre o passado e o futuro. Tradução de Mauro W. Barbosa. 7. ed. São Paulo: Perspectiva, 2013.

ARENDT, H. A vida do espirito. Tradução de Antonio Abranches e Helena Martins. 2. ed. Rio de Janeiro: Relume Dumará/ED. UFRJ, 1993.

DELEUZE, G. Diferença e repetição. Rio de Janeiro: Graal, 1988.

DELEUZE, G. \& GUATTARI, F. O que é a filosofia? Rio de Janeiro: Ed. 34, 1992.

KANT, I. Crítica da Razão Pura; Trad. Valério Rohden e Uno Baldur Mooosburger. 2. Ed. São Paulo: Abril Cultura, 1983.

NIETZSCHE, F. Ecce Hommo: como alguém se torna o que é. São Paulo: Cia das Letras, 1995.

NIETZSCHE, F. Assim falou Zaratustra. 7. ed. Rio de Janeiro: Bertrand Brasil, 1994.

NIETZSCHE, F. Além do bem e do mal. São Paulo: Cia das Letras, 1992.

PLATÃO. O banquete - Apologia de Sócrates. Tradução de Carlos Alberto Nunes. 2. ed. Belém: Editora Universitária da UFPA, 2001.

POMBO, Olga. A Escola, a Recta e o Círculo. Lisboa: Relógio d’Água, 2002.

SANTOS, B. S. Para uma sociologia das ausências e uma sociologia das emergências. In: SANTOS, B. S. O conbecimento prudente para uma vida decente. São Paulo: Cortez, 2004.

SANTOS, B. S. Um discurso sobre as ciências. 5. ed. São Paulo: Cortez, 2008.

SAVATER, F. As perguntas da vida. São Paulo: Martins Fontes, 2001.

SAVATER, F. O meu dicionário filosófico. Lisboa: Dom Quixote, 2000.

Submetido em: 07/12/2017

Aceito em: 15/05/2018

Publicado em: 15/10/2018

Filos. e Educ., Campinas, SP, v.10, n.2, p.331-349, maio/ago. 2018 - ISSN 1984-9605 